\title{
Participation of rural patients in clinical trials at a multisite academic medical center
}

www.cambridge.org/cts

\section{Implementation, Policy and Community Engagement Research Article}

Cite this article: Bharucha $\mathrm{AE}, \mathrm{Wi} \mathrm{Cl}$, Srinivasan SG, Choi H, Wheeler PH, Stavlund JR, Keller DA, Bailey KR, and Juhn YJ. Participation of rural patients in clinical trials at a multisite academic medical center. Journal of Clinical and Translational Science 5: e190, 1-10. doi: $10.1017 /$ cts. 2021.813

Received: 2 March 2021

Revised: 9 June 2021

Accepted: 2 July 2021

\section{Keywords:}

Clinical trial; geocoding; recruitment; rural; urban

\section{Address for correspondence:}

A. E. Bharucha, MBBS, MD, Division of Gastroenterology and Hepatology, Mayo Clinic, 200 First St SW, Rochester, MN 55905, USA; Phone: 507-284-2687.

Email: bharucha.adil@mayo.edu
Adil E. Bharucha ${ }^{1}$, Chung II Wi², Sushmitha Grama Srinivasan ${ }^{3}$, Hyuckjae Choi ${ }^{2}$, Phillip H. Wheeler ${ }^{2}$, Jennifer R. Stavlund ${ }^{4}$, Daniel A. Keller ${ }^{5}$, Kent R. Bailey ${ }^{6}$ and

Young J. Juhn²

${ }^{1}$ Division of Gastroenterology and Hepatology, Mayo Clinic, Rochester, MN, USA; ${ }^{2}$ Department of Pediatric and Adolescent Medicine, Mayo Clinic, Rochester, MN, USA; ${ }^{3}$ Mayo Clinic School of Graduate Medical Education, Mayo Clinic College of Medicine and Science, Rochester, Minnesota, USA; ${ }^{4}$ Department of Research Administration, Mayo Clinic, Rochester, MN, USA; ${ }^{5}$ Enterprise Application Services, Mayo Clinic, Rochester, MN, USA and ${ }^{6}$ Division of Computational Biology, Mayo Clinic, Rochester, MN, USA

\begin{abstract}
Objective: Clinical trials, which are mainly conducted in urban medical centers, may be less accessible to rural residents. Our aims were to assess participation and the factors associated with participation of rural residents in clinical trials. Methods: Using geocoding, the residential address of participants enrolled into clinical trials at Mayo Clinic locations in Arizona, Florida, and the Midwest between January 1, 2016, and December 31,2017, was categorized as urban or rural. The distance travelled by participants and trial characteristics was compared between urban and rural participants. Ordinal logistic regression analyses were used to evaluate whether study location and risks were associated with rural participation in trials. Results: Among 292 trials, including 136 (47\%) cancer trials, there were 2313 participants. Of these, 731 (32\%) were rural participants, which is greater than the rural population in these 9 states $(19 \%, P<0.001)$. Compared to urban participants, rural participants were older ( $65 \pm 12$ years vs $64 \pm 12$ years, $P=0.004)$ and travelled further to the medical center $(103 \pm 104$ vs $68 \pm 88$ miles, $P<0.001)$. The proportion of urban and rural participants who were remunerated was comparable. In the multivariable analysis, the proportion of rural participants was lower $(P<0.001)$ in Arizona (10\%) and Florida (18\%) than the Midwest (38\%) but not significantly associated with the study-related risks. Conclusions: Approximately one in three clinical trial participants were rural residents versus one in five in the population. Rural residents travelled further to access clinical trials. The study-associated risks were not associated with the distribution of rural and urban participants in trials.
\end{abstract}

(c) The Author(s), 2021. Published by Cambridge University Press on behalf of The Association for Clinical and Translational Science. This is an Open Access article, distributed under the terms of the Creative Commons AttributionNonCommercial-NoDerivatives licence (http:// creativecommons.org/licenses/by-nc-nd/4.0/), which permits non-commercial re-use, distribution, and reproduction in any medium, provided the original work is unaltered and is properly cited. The written permission of Cambridge University Press must be obtained for commercial re-use or in order to create a derivative work.

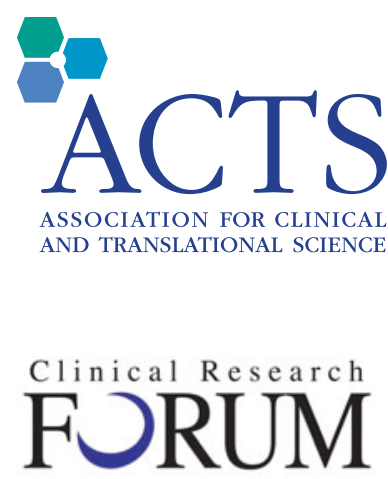

Analysis. Adrocacy. Action.

\section{Background}

Rural residents, who comprise approximately $19 \%$ of the US population, are prone to health disparities [1, 2]. At birth, they have a shorter life expectancy than urban residents [3]. About $70 \%$ of the gap between urban and rural life expectancy, which has increased over time, is accounted for by heart disease, unintentional injuries, cerebrovascular disease, chronic obstructive pulmonary disease, and lung cancer, which in turn, may partly reflect differences in behavioral and health care factors, including higher smoking and obesity rates and lower access to health care [3]. For example, from 2011 to 2015, the age-adjusted rate of cancer deaths per 100,000 individuals was 180.4 in rural areas but 157.8 in large metropolitan areas, which may be partly explained by reduced access to health care or financial resources for rural individuals [4]. Whether this geographic disparity is explained by limited access to a broad range of health care resources, such as quality care or access to clinical trials, is unclear.

Especially beneficial for patients with complex conditions, clinical trials provide access to potentially effective options before they are approved for routine use [5]. Centers that offer trials may also have better outcomes because they are more likely to have multidisciplinary teams that provide state-of-the-art management. It is suggested that rural participants have limited access to clinical trials, which are predominantly conducted at urban medical centers [6-9]. Indeed, the 174,503 clinical trial sites in the US Food and Drug Administration (FDA) Bioresearch Monitoring System between 2002 and 2007 were highly clustered around urban areas with health care and/or social service facilities [7]. However, to our knowledge, few studies have systematically evaluated the distribution of urban and rural residents among patients who participate in trials. Among 36,995 cancer patients from all 50 states enrolled in phase 3 and 2/3 trials in the Southwestern Oncology Group, 19.4\% of patients were rural residents; rural and urban patients had comparable outcomes [10]. This proportion (19.4\%) is 
comparable to the corresponding proportion in the US rural population [2], which suggests that contrary to the impression [6-9], urban and rural patients have comparable participation rates in clinical trials supported by the National Cancer Institute, which incorporate community outreach programs. However, that analysis was limited to patients with cancer. Because the rural population (\%) varies from $0 \%$ in the District of Columbia to $50.65 \%$ in Mississippi, the proportion of rural patients in trials and the population should be compared state wise. Other factors, such as the study risks, travel burden, and financial benefits that influence the willingness to participate in trials, also need to be considered [11]. For example, among elderly people from an underserved population, financial compensation and transportation were the primary concerns about participation in research, respectively, in urban and rural groups [12].

To address these questions, the aims of this study were to 1) compare the proportion of rural and urban people who participate in clinical trials at an academic medical center with three geographically diverse practice sites, which deliver health care to both urban and rural populations; 2) compare the proportion of rural residents in clinical trials with the corresponding proportions in the overall population and our overall practice; and 3) assess whether participant age, sex, and selected factors that are associated with the willingness to participate in trials (e.g., study risks, remuneration, and travel burden) influence the participation of rural versus urban participants. These are important questions because lower rates of participation among rural residents and other minorities affect the generalizability of trial results [13]. Indeed, the National Institutes of Health have emphasized the need to include special populations, including rural participants, in clinical trials [9].

\section{Materials and Methods}

\section{Experimental Design}

This project was approved by the Mayo Clinic Institutional Review Board (IRB). We identified participants enrolled in 292 industry-sponsored clinical trials activated between January 1, 2016, and December 31, 2017, at three Mayo Clinic campuses - Arizona, Florida, and the Midwest. The Midwest includes Mayo Clinic in Rochester, Minnesota, and the Mayo Clinic Health System locations in Minnesota, Wisconsin, and Iowa. As of March 15, 2019, 2874 participants had been enrolled into these trials and of these, 456 (16\%) participants were excluded for 1 or more reasons:

1. Twenty-one participants did not have a medical record number and 1 participant did not provide an address.

2. One hundred and nineteen patients had participated in two or more studies. In these patients, only the first study was considered for data analysis.

3. To reduce the risk that the data were skewed, 315 participants who were residents of countries outside the USA or states (e., Alabama, Arkansas, California) that are outside the primary catchment area for any Mayo Clinic location (please see below), and 32 participants who reside in a state that is outside the primary catchment area for the specific Mayo Clinic location were excluded from analysis.
Of the remaining 2386 participants, residential geocoding, which was based on the longitude and latitude of the residential address, was possible in 2313 participants [14]. For Mayo Clinic in the Midwest, the catchment area for trial participants included Minnesota, Iowa, Illinois, Wisconsin, North Dakota, or South Dakota. For Mayo Clinic in Florida, the corresponding catchment area was Florida and Georgia. At Mayo Clinic in Arizona, the catchment area was Arizona. The residential address was categorized as urban or rural based on the census definition [2]. Urbanized areas of 50,000 or more people and urban clusters of at least 2500 and less than 50,000 people were considered urban while rural encompasses all population, housing, and territory not included within an urban area. The approximate distance between the residential address and the medical center was expressed as airline miles. To account for the shorter distance between lines of longitude and the latitude in Mayo Clinic in the Midwest, the estimated miles were calculated by assuming a relationship of 60 miles per degree of longitude at Mayo Clinic in Florida and in Arizona and 55 miles per degree at Mayo Clinic in Rochester and the Mayo Clinic Health System at La Crosse, Wisconsin.

\section{Data Analysis}

The characteristics of these studies was extracted from the Mayo Clinic IRB and PTrax (Clinical Trial Participant Tracking system, Mayo Clinic) databases [15]. The risks associated with studies were extracted from the IRB database and categorized as follows: 1) blood draws, 2) use of drugs or biologic agents; 3) use of drugs or biological agents requiring US FDA review; 4) use of medical or educational records; 5) ionizing radiation; 6) any invasive procedures; 7) use of medical devices; 8) use of medical devices that require FDA review; 9) use of recombinant DNA or human gene transfer; 10) infectious agents; and 11) human stem cells, embryos, or their derivatives. The remuneration to study participants was categorized as fixed (e.g., per study visit), expense-based (e.g., based on miles travelled and/or expenses for boarding and lodging), or both. There are different classifications for urban versus rural areas. Some, such as by Rural-Urban Commuting Area (RUCA), are partly defined by the proportion of the population that commutes to a metropolitan location [16]. Because the distance commuted is an endpoint of this study, we used the United States Census data from 2010 to determine the urban and rural composition. This system is based on population size, land use, and the distance between a location and the nearest urban area but does not, by contrast to RUCA, incorporate the proportion of the population that commutes to urban area(s) [17]. The proportion of all Mayo Clinic patients (Midwest, Florida, and Arizona) who were rural residents was estimated in a random sample of $10 \%$ of all Mayo Clinic patients (i.e., those who had a primary care provider at Mayo Clinic) in 2017.

\section{Statistical Analysis}

Continuous variables were compared using the Wilcoxon rank sum or Kruskal-Wallis test as appropriate. Categorical data were analyzed with the $\chi^{2}$ test. The proportion of rural residents in the population of these states was compared with the proportion of rural participants in trials and separately with the proportion of rural Mayo Clinic patients using the 1-sample binomial test; for the purpose of analysis, this was regarded as fixed and known. Ordinal logistic regression was used to predict whether the risks 
associated with studies predicted the proportion of rural participants in each trial (dependent variable) $[18,19]$. Among studies, the proportion of rural residents varied considerably, from $0 \%$ to $100 \%$. Ordinal regression models are an extension of binary logistic regression models. By contrast to the latter, ordinal models are semi-parametric models in which the dependent variable and predictor variables are respectively treated nonparametrically and parametrically. The dependent variable (i.e., proportion of rural residents) is considered as a rank variable, which allows the parametric function for the $\log$ (odds) (of being at a higher versus lower value) to be estimated. The models only evaluated risks that were each associated with studies that enrolled more than 100 participants. There were eight models corresponding to the individual risks (i.e., blood draws, drugs or biologic agents, drugs or biologic agents that require FDA review, medical or educational records, ionizing radiation, any invasive procedures, medical devices, and medical devices that require FDA review) and another model included all risks. Each model was adjusted for the proportion of participants in Arizona and Florida (Midwest acting as reference), to account for differences in proportion of urban versus rural residents at the three locations. All values have been expressed as mean \pm SD unless stated otherwise. The statistical analyses were performed with JMP Pro, version 14.0.0. (SAS Institute Inc).

\section{Results}

\section{Characteristics of Trials}

Of the 292 trials, 212 (73\%), 90 (31\%), and 77 (26\%) were conducted at Mayo Clinic locations in the Midwest, Arizona, and Florida, respectively (Table 1). A majority (i.e., 253 trials [87\%]) were conducted as a single-site study. The remainder were conducted at two or three Mayo Clinic sites. Of the 292 trials, 285 (98\%) posed greater than a minimal risk to participants (Table 1) and 136 (47\%) were cancer trials. The most frequent risks associated with these trials include blood draws 265 (91\%), use of drugs or biological agents $250(86 \%)$, and use of medical or educational materials 209 (72\%). Compared to rural participants, urban participants were more likely to participate in trials that were evaluating medical devices which required FDA review (74 [59\%] vs 51 [41\%]; $P=0.02)$ or ionizing radiation $(672[71 \%]$ vs 277 [29\%]; $P=0.04$ ). Two hundred and twenty trials $(76 \%)$ offered to reimburse expenses and/or remunerate participants. The remuneration was a fixed, typically, per-visit (106 trials [36\%]), expense-based (88 trials [30\%]), or both (26 trials [9\%]).

\section{Rural or Urban Residential Status}

The residential addresses were geocoded and categorized as urban or rural in 2313 of 2386 (97\%) trial participants; this proportion ranged from 37 of 42 (88\%) for participants from South Dakota to 1130 of 1155 (98\%) for participants from Minnesota (Table 2). Based on geography (US Census 2010), 96\% of the 9 states overall are considered as a rural area while only 731 (32\%) participants resided in a rural area (Table 3 ). This proportion ranged from 26 of 266 (10\%) in Arizona to 96 of 157 (61\%) in Wisconsin (Table 3). The proportion of rural clinical trial participants was different across the Mayo Clinic locations, being greater $(P<0.001)$ in the Midwest (634 of 1663 participants; 38\%) compared to Arizona (26 of 266 participants; $10 \%$ ) and Florida (71 of 384 participants; 18\%) (Table 1; Figs. 1 and 2).

\section{Demographic Features}

Trial participants at Mayo Clinic in Florida were older $(66 \pm 11$ years) than participants in Arizona (64 \pm 11 years) and the Midwest $(64 \pm 12$ years $)(P<0.001)$. The proportion of women was also different $(P<0.001)$ among sites, being lower in Florida (156 of 384 participants; 41\%) than in Arizona (145 of $266 ; 54 \%$ ) and the Midwest (826 of $1663 ; 50 \%$ ).

Across all sites, rural participants were older than urban trial participants ( $65 \pm 12$ years vs $64 \pm 12$ years; $P=0.004)$. These differences were most pronounced in the Midwest, where rural and urban participants were aged $65 \pm 12$ years and $63 \pm 12$ years, respectively $(P<0.001)$. By contrast, the age of rural and urban participants was comparable in Arizona and Florida $(P=0.3$ and $P=0.6$, respectively). Overall, 1182 (51\%) participants were aged 65 and older and 163 (7\%) participants were aged 80 years and older (Fig. 2). In the Midwest, 322 (51\%) of rural versus $445(43 \%)$ of urban participants were aged 65 years or older $(P=0.002) ; 65(10 \%)$ of rural and $68(7 \%)$ of urban participants were aged 80 years or older $(P=0.008)$. However, at Mayo Clinic locations in Arizona and Florida, these proportions were not different between urban and rural participants.

Compared to the 7 minimal risk trials, the participants in the 285 greater than minimal risk trials were older ( $65 \pm 12$ years vs $63 \pm 9$ years; $P<0.001)$. However, the proportion of women was not different $(P=0.1)$ between minimal and greater than minimal risk trials. The proportion of rural and urban trial participants who were remunerated for participating in a trial was not different $(P=0.2)$. The proportion of rural participants in cancer and noncancer trials was comparable $(30 \pm 28 \%$ and $28 \pm 30 \% ; P=0.2$ ).

\section{Comparison of Residential Status in Trial Participants vs Mayo Clinic Patients and United States Census Data}

Based on the population size and density, 11,039,118 (19\%) people of the population in these 9 states resided in a rural area (Table 3 ). Compared to the proportion of rural residents in these 9 states, a greater proportion of Mayo Clinic patients were rural residents (36\% vs $19 \% ; P<0.001$ ) (Table 3 ). Similar differences were observed for all states except for patients from Arizona, North Dakota, and South Dakota.

The proportion of rural trial participants was greater than the rural population in these 9 states $(32 \%$ vs $19 \% ; P<0.001)$ (Table 3$)$. Similar differences were observed for all states except Arizona and North Dakota. Overall, the proportions of rural clinical trial participants and rural Mayo Clinic patients were 32\% and 36\%, respectively. These differences varied among states. Compared to the proportion of rural Mayo Clinic patients, the proportion of rural clinical trial participants was lower $(P<0.05)$ in Minnesota (33 vs 37\%) and Iowa (45 versus 58\%), greater $(P<0.01)$ in Wisconsin $(61$ vs $50 \%)$, and comparable in Arizona, Florida, Georgia, Illinois, North Dakota, and South Dakota.

\section{Distance Travelled by Urban versus Rural Clinical Trial Participants}

Rural participants travelled further than urban participants overall $(103 \pm 104$ vs $68 \pm 88$ miles; $P<0.001)$ (Table 4; Fig. 3$)$ and at each site (i.e., Arizona, Florida, and Midwest). 
Table 1. Study characteristics

\begin{tabular}{|c|c|c|c|c|c|}
\hline Feature & Trials, no. (\%) & Participants, no. & $\begin{array}{c}\text { Urban participants, } \\
\text { no. (\%) }\end{array}$ & $\begin{array}{c}\text { Rural participants, } \\
\text { no. }(\%)\end{array}$ & $P$ value $^{\mathrm{a}}$ \\
\hline \multicolumn{6}{|l|}{ Location } \\
\hline Florida & $77(26)$ & 384 & $313(81)$ & $71(18)$ & \\
\hline Midwest & $212(73)$ & 1663 & $1029(62)$ & $634(38)$ & \\
\hline \multicolumn{6}{|l|}{ Type of study risk(s) } \\
\hline Minimal risk & $7(2)$ & 285 & $191(67)$ & $94(33)$ & 0.6 \\
\hline Greater than minimal risk & $285(98)$ & 2028 & $1391(69)$ & $637(31)$ & \\
\hline \multicolumn{6}{|l|}{ Study risks } \\
\hline Blood draws & $265(91)$ & 1779 & $1222(69)$ & $557(31)$ & 0.6 \\
\hline Use of drugs or biological agents & $250(86)$ & 1576 & $1091(69)$ & $485(31)$ & 0.2 \\
\hline Use of ionizing radiation & $152(52)$ & 949 & $672(71)$ & $277(29)$ & 0.04 \\
\hline Any invasive procedure(s) & $145(50)$ & 1029 & $715(69)$ & $314(31)$ & 0.3 \\
\hline Use of medical devices & $55(20)$ & 735 & $483(66)$ & $252(34)$ & 0.06 \\
\hline Use of medical devices that require FDA review & $16(5.5)$ & 125 & $74(59)$ & $51(41)$ & 0.02 \\
\hline Use of recombinant DNA or human gene transfer & $3(1)$ & 13 & $8(62)$ & $5(38)$ & 0.6 \\
\hline Infectious agents & $2(0.7)$ & 4 & $2(50)$ & $2(50)$ & 0.4 \\
\hline Human stem cells, human embryos, or their derivatives & $1(0.3)$ & 1 & $1(100)$ & $0(0)$ & 0.5 \\
\hline Remuneration & $221(76)$ & 1518 & $1052(69)$ & $466(31)$ & 0.2 \\
\hline
\end{tabular}

FDA, US Food and Drug Administration.

${ }^{a} \chi^{2}$ test comparing the proportion of rural versus urban clinical trial participants by location, type of study risk(s), study risks, and remuneration.

Table 2. Residential status of clinical trial participants at Mayo Clinics in Arizona, Florida, and Midwest

\begin{tabular}{|c|c|c|c|c|c|c|c|c|}
\hline $\begin{array}{l}\text { State (participant's residential } \\
\text { address) }\end{array}$ & $\begin{array}{l}\text { Total, } \\
\text { no. }\end{array}$ & $\begin{array}{l}\text { Non-geocoded, } \\
\text { no. }\end{array}$ & $\begin{array}{l}\text { Geocoded, } \\
\text { no. }\end{array}$ & $\begin{array}{l}\text { Geocoding, } \\
\%\end{array}$ & $\begin{array}{l}\text { Urban area }{ }^{a}, \\
\text { no. }\end{array}$ & $\begin{array}{l}\text { Urban cluster } \\
\text { no. }\end{array}$ & $\begin{array}{c}\text { Rural, } \\
\text { no. }\end{array}$ & $\begin{array}{c}\text { Rural, } \\
\%\end{array}$ \\
\hline Arizona $^{c}$ & 275 & 9 & 266 & 97 & 229 & 11 & 26 & 10 \\
\hline Georgia $^{d}$ & 46 & 6 & 40 & 87 & 17 & 8 & 15 & 38 \\
\hline Minnesota ${ }^{e}$ & 1155 & 25 & 1130 & 98 & 537 & 218 & 375 & 33 \\
\hline Illinois ${ }^{e}$ & 75 & 2 & 73 & 97 & 43 & 8 & 22 & 30 \\
\hline Wisconsin ${ }^{e}$ & 162 & 5 & 157 & 97 & 41 & 20 & 96 & 61 \\
\hline North Dakota & 40 & 3 & 37 & 93 & 15 & 5 & 17 & 46 \\
\hline South Dakota & 42 & 5 & 37 & 88 & 5 & 11 & 21 & 57 \\
\hline All 9 States & 2386 & 73 & 2313 & 97 & 1222 & 360 & 731 & 32 \\
\hline
\end{tabular}

aUrban area has a population of 50,000 or more.

bUrban cluster has a population of at least 2500 and less than 50,000.

'Participants from Arizona only were enrolled in a clinical trial at Mayo Clinic in Arizona.

dParticipants from Georgia were enrolled in a clinical trial at Mayo Clinic in Florida.

eparticipants in these states were enrolled in a clinical trial at Mayo Clinic in the Midwest.

Relationships Between Proportion of Rural Participants, Risks of Studies, and Residential Status

All the models in Table 5 were adjusted for proportion of participants in study location (Midwest acting as reference). The risks were considered individually in models $1-8$ and concurrently in model 9.

Compared to the Midwest, the proportion of rural participants in clinical trials was lower in Arizona and Florida (estimate [standard error $]=-2[0.3]$, and $-1[0.3] ; P<0.001)$ (models $1-9$, 
Table 3. Rural/Urban status: comparison of clinical trial participants at Mayo Clinic with US population

\begin{tabular}{|c|c|c|c|c|c|c|c|}
\hline \multirow{2}{*}{$\begin{array}{l}\text { State } \\
\text { (participant's } \\
\text { residential } \\
\text { address) }\end{array}$} & \multicolumn{2}{|c|}{$\begin{array}{l}\text { Proportion of rural area or population } \\
\text { (US Census 2010) }\end{array}$} & \multirow{2}{*}{$\begin{array}{l}\text { Proportion of } \\
\text { rural residents } \\
\text { among Mayo } \\
\text { Clinic adult } \\
\text { patients, no.; \% }\end{array}$} & \multirow{2}{*}{$\begin{array}{l}\text { Proportion of rural } \\
\text { residents among } \\
\text { clinical trial partici- } \\
\text { pants at Mayo } \\
\text { Clinic } \\
\text { 2016-2017, no.; \% }\end{array}$} & \multirow[b]{2}{*}{$P$ value $^{a}$} & \multirow[b]{2}{*}{$P$ value $^{\mathrm{b}}$} & \multirow[b]{2}{*}{$P$ value } \\
\hline & $\begin{array}{l}\text { Geography, } \\
\%\end{array}$ & $\begin{array}{l}\text { Population size and } \\
\text { density, no.; } \%\end{array}$ & & & & & \\
\hline Arizonad $^{d}$ & 98 & $651,358(6,392,017) ; 10$ & 899 (9467); 10 & $26(266) ; 10$ & 0.9 & 0.5 & 0.9 \\
\hline Florida & 86 & $1,661,466(18,801,310) ; 8$ & 1478 (9558); 15 & 56 (344); 16 & $<0.0001$ & $<0.0001$ & 0.7 \\
\hline Georgiae $^{e}$ & 92 & $2,415,502(9,687,653) ; 25$ & 432 (1027); 42 & 15 (40); 38 & $<0.0001$ & 0.03 & 0.6 \\
\hline Minnesota $^{f}$ & 98 & 1,417,614 (5,303,925); 27 & $14,567(39,760) ; 37$ & 375 (1130); 33 & $<0.0001$ & $<0.0001$ & 0.02 \\
\hline lowa ${ }^{f}$ & 98 & $1,096,099(3,046,355) ; 36$ & 2551 (4412); 58 & 103 (229); 45 & $<0.0001$ & 0.002 & 0.0001 \\
\hline Illinois ${ }^{f}$ & 93 & $1,477,079(12,830,632) ; 12$ & 415 (1699); 24 & 22 (73); 30 & $<0.0001$ & $<0.0001$ & 0.3 \\
\hline Wisconsin ${ }^{f}$ & 97 & 1,697,348 (5,686,986); 30 & $10,284(20,617) ; 50$ & 96 (157); 61 & $<0.0001$ & $<0.0001$ & 0.005 \\
\hline North Dakota ${ }^{f}$ & 99 & $269,719(672,591) ; 40$ & 362 (870); 42 & $17(37) ; 46$ & 0.1 & 0.2 & 0.6 \\
\hline South Dakota ${ }^{f}$ & 99 & $352,933(814,180) ; 43$ & 286 (637); 45 & $21(37) ; 57$ & 0.1 & 0.03 & 0.1 \\
\hline All 9 States & 96 & $11,039,118(63,235,649) ; 19$ & $31,274(88,047) ; 36$ & 731 (2313); 32 & $<0.0001$ & $<0.0001$ & NA \\
\hline
\end{tabular}

${ }^{a}$ One sample binomial test comparing proportion of rural population (US Census 2010) and proportion of Mayo Clinic adult patients.

${ }^{b}$ One sample binomial test comparing proportion of rural population (US Census 2010) and proportion of rural clinical trial participants.

${ }^{c} \chi^{2}$ test comparing proportion of Mayo Clinic adult patients and proportion of rural clinical trial participants.

dParticipants from Arizona only were enrolled in a clinical trial at Mayo Clinic in Arizona.

eParticipants from Georgia were enrolled in a clinical trial at Mayo Clinic in Florida.

fParticipants in these states were enrolled in a clinical trial at Mayo Clinic in the Midwest.

Table 5, Fig. 1) but not significantly associated with studyrelated risks.

\section{Discussion}

This study was assisted by geocoding and a unique application (PTrax) that is used to consent participants and track their flow through the trials at Mayo Clinic. In contrast to IRB progress reports, which are typically updated annually, the PTrax system tracks enrollment in real time. Among 2313 people who participated in 292 cancer and noncancer clinical trials at our institution, rural participants, aged 65 years average, travelled further to reach a medical facility. Despite that, approximately 1 in 3 trial participants were rural residents, which is greater than the corresponding proportion $(20 \%)$ in the population. The proportion of rural trial participants (32\%) was numerically comparable to the proportion of all rural patients at our institution (36\%), probably because physicians in the clinical practice refer a majority of patients who participate in clinical trials $[20,21]$. Patients who are engaged in a health system are also more likely to complete follow-up in a clinical trial [22]. The study remuneration and risks did not affect the ratio of rural:urban participants in trials.

Clinical trials are a robust source of scientific evidence that are vital to discovering new options for the diagnosis and treatment of disease. It has been suggested that rural participants have limited access to clinical trials as the majority of them are conducted in urban medical centers [6-9]. Of the several definitions for the word rural [8], this study used the United States Census Bureau definition for a rural area, that is, "any population, housing, or territory not in an urban area" [2]. Urbanized areas have a population of 50,000 or more, while urban clusters have a population of at least 2500 and less than 50,000 [2]. According to this relatively broad definition, all three primary Mayo Clinic locations, including Rochester, Minnesota, are located in an urban area. However, residents in the surrounding rural communities have access to-and receive their primary care-at an urban Mayo Clinic location.

Participation in trials is characterized by three stages or transitions: trial availability, patient interest, and patients consented [23]. An analysis of 7735 clinical trials observed that between 1991 and 2001, the proportion of academic clinical sites in clinical trials decreased steadily from $70 \%$ of US sites in 1991 to $35 \%$ in 2001 ; while the number of academic clinical sites was static, the number of non-academic sites increased considerably [24]. Most academic medical centers are located in urban areas, and arguably less accessible to rural residents [7]. Indeed, of the 50 top National Institutes of Health-funded research centers in 2020 [25], 49 are located in urban areas according to the United States Census Bureau; only 7 are located in counties where the rural population is $10 \%$ or greater. The latter group includes the University of Wisconsin at Madison, Wisconsin (12\%), University of Michigan at Ann Arbor, Michigan (16\%), Mayo Clinic Rochester, Minnesota (16\%), University of Massachusetts Medical School, Worcester, Massachusetts (18\%), University of Iowa, Iowa City, Iowa (18\%), University of North Carolina at Chapel Hill, Chapel Hill, North Carolina (28\%), and University of Virginia, Charlottesville, Virginia (45\%). In this study, rural residents participated in trials even though, on average, they travelled 35 miles further than urban participants to reach a Mayo Clinic facility. Similarly, rural residents travel about 8 miles further than urban residents to access health care in the USA [26]. Four times as many rural than urban residents travel 30 miles or further to access health care [26]. The time commitment and inconvenience of participation in clinical trials are greater for rural than urban residents [11], especially when trials include multiple in-person follow-up visits. Indeed, among elderly people in an underserved population, the primary concerns about participation in research related to financial compensation and transportation in urban and rural groups [12]. 


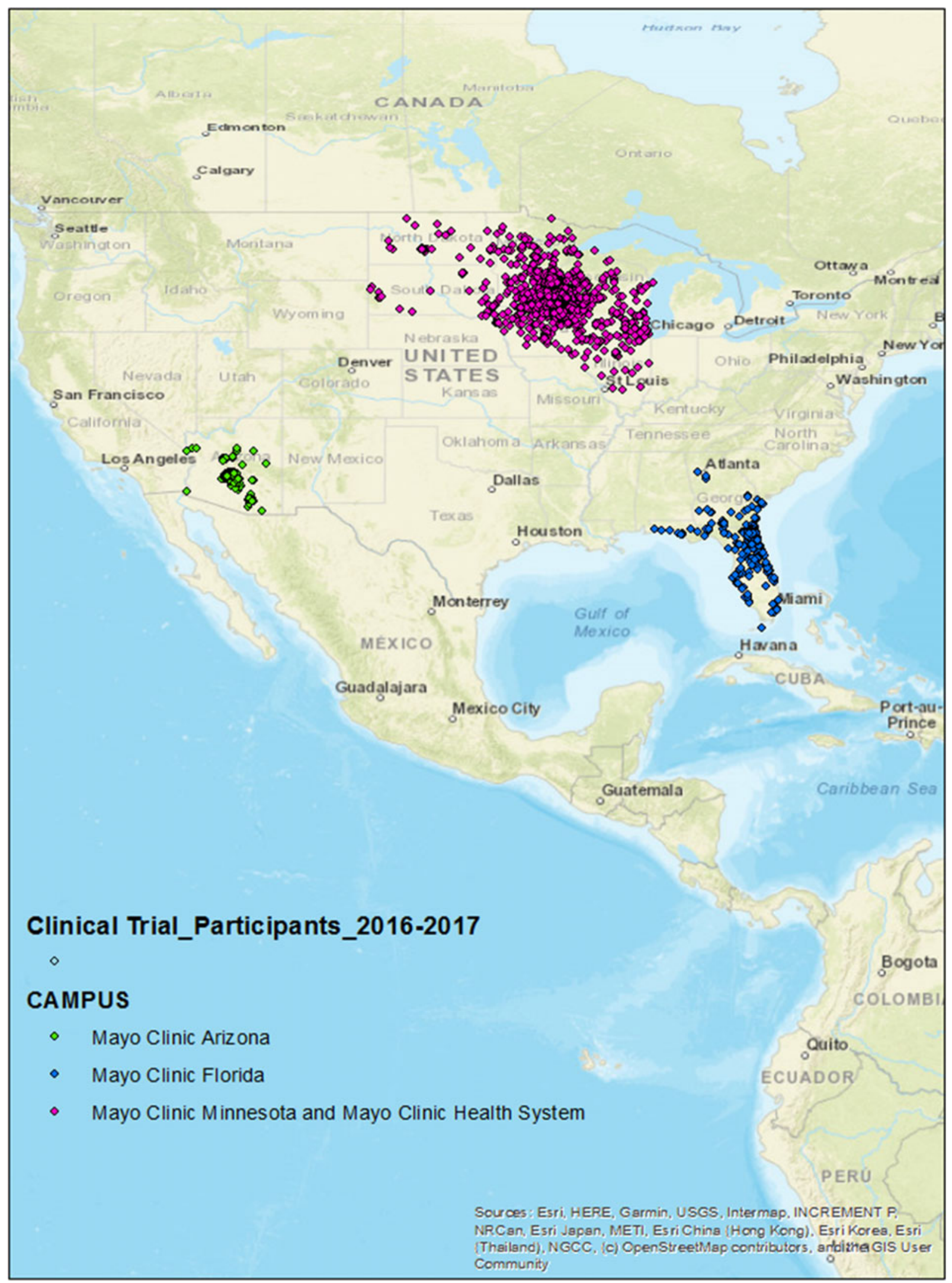

Fig. 1. Distribution of the residential address of trial participants. These participants resided in nine states (Minnesota, Wisconsin, Illinois, lowa, North Dakota, South Dakota, Florida, Georgia, and Arizona). (Source: ArcMap 10.7, ESRI). 
Table 4. Distances travelled by trial participants at Mayo Clinic residing in urban and rural areas

\begin{tabular}{|c|c|c|c|c|c|c|c|}
\hline \multirow[b]{2}{*}{$\begin{array}{l}\text { Mayo Clinic } \\
\text { location }\end{array}$} & \multirow[b]{2}{*}{ All participants, no. } & \multirow{2}{*}{$\begin{array}{c}\text { Urban } \\
\text { participants, } \\
\text { no. }(\%)^{a}\end{array}$} & \multirow{2}{*}{$\begin{array}{c}\text { Rural } \\
\text { participants, } \\
\text { no. }(\%)^{a}\end{array}$} & \multicolumn{3}{|c|}{ Distance travelled, miles } & \multirow[b]{2}{*}{$P$ value ${ }^{c}$} \\
\hline & & & & $\begin{array}{c}\text { All } \\
\text { participants }\end{array}$ & $\begin{array}{c}\text { Urban } \\
\text { participants }\end{array}$ & $\begin{array}{c}\text { Rural } \\
\text { participants }\end{array}$ & \\
\hline Arizona & 266 & $240(90)$ & $26(10)$ & $29 \pm 35$ & $27 \pm 33$ & $50 \pm 44$ & 0.003 \\
\hline Florida & 384 & $313(82)$ & $712(18)$ & $67 \pm 76$ & $65 \pm 78$ & $76 \pm 63$ & 0.002 \\
\hline Midwest & 1663 & $1029(62)$ & $778(38)$ & $90 \pm 102$ & $79 \pm 96$ & $108 \pm 108$ & $<0.0001$ \\
\hline Overall & 2313 & $1582(68)$ & 731 (32) & $79 \pm 94$ & $68 \pm 88$ & $103 \pm 104$ & $<0.0001$ \\
\hline
\end{tabular}

Values are mean \pm SD unless stated otherwise.

aPercentages are row percentages.

${ }^{\mathrm{b}} P<0.0001$; Kruskal-Wallis test comparing distance travelled by clinical trial participants by the 3 Mayo Clinic locations.

'Wilcoxon rank sum test comparing the distance travelled by rural and urban participants at each Mayo Clinic location.

Seventy-three subjects whose addresses were not geocoded were excluded (e.g., PO BOX address).

A

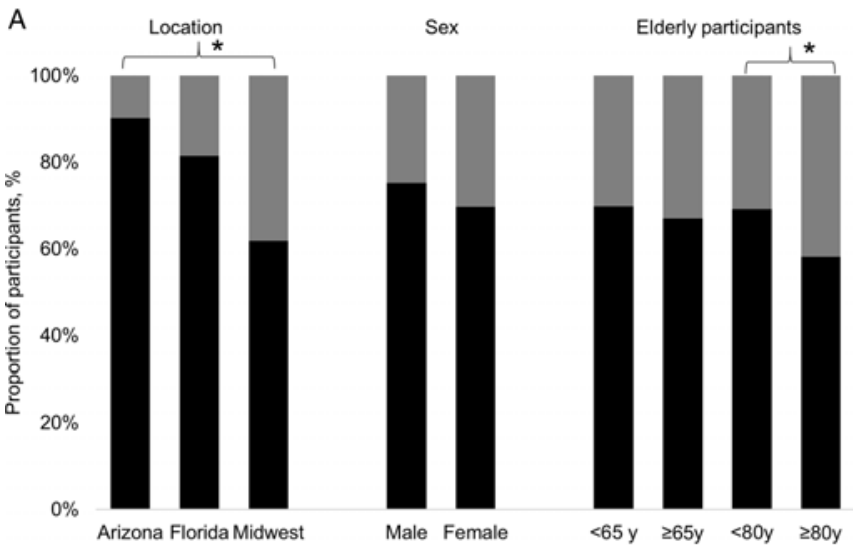

B

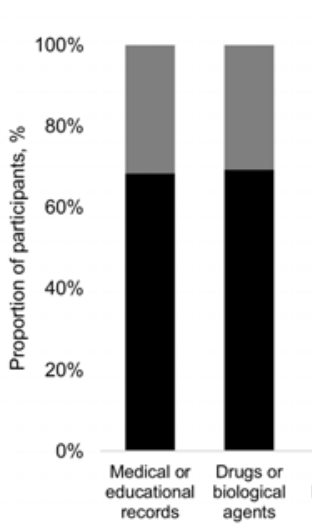

Trial risks
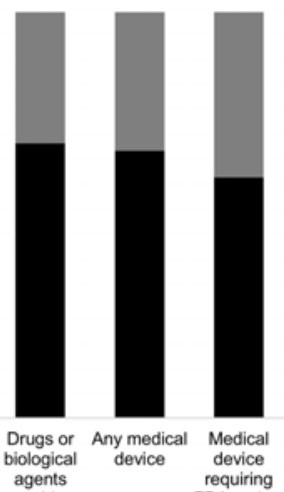

Medical
device requiring
FDA review

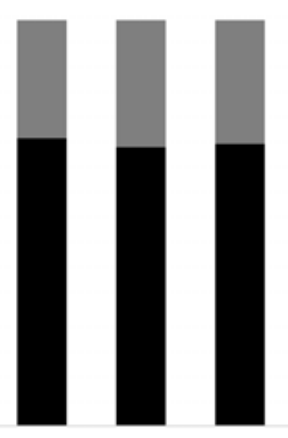
lonizing Blood draw Any invasive
radiation
procedure procedure

\section{- Urban Rural}

* $P$ for chi-square <.05

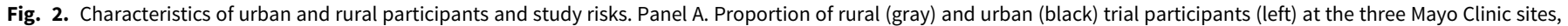

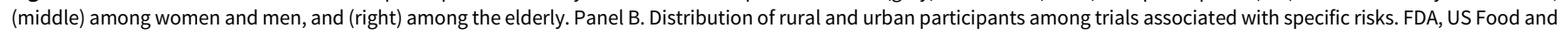
Drug Administration.

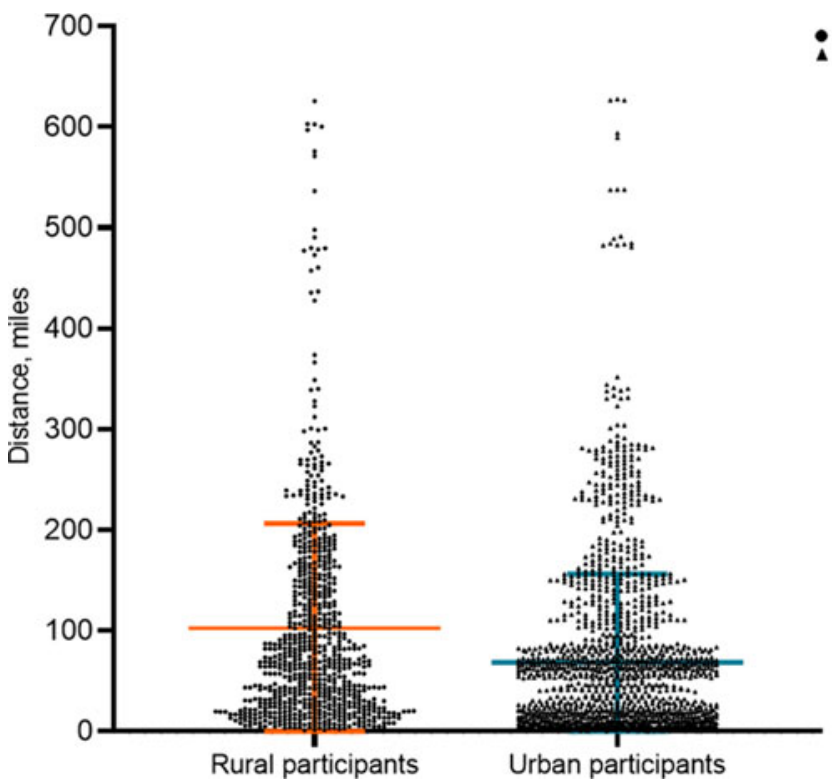

Fig. 3. Distance in miles travelled by rural and urban participants to reach trial location. Mean distance and standard deviation represented by orange and blue lines, respectively, in rural and urban participants. 
Table 5. Multivariable ordinal logistic regression models to predict proportion of rural clinical trial participants ${ }^{a}$

\begin{tabular}{|c|c|c|c|c|c|c|c|c|c|c|}
\hline \multirow[b]{2}{*}{ Model } & \multirow[b]{2}{*}{$\begin{array}{l}\text { Participants } \\
\text { from Arizona }{ }^{b}\end{array}$} & \multirow[b]{2}{*}{$\begin{array}{l}\text { Participants } \\
\text { from Florida }\end{array}$} & \multicolumn{8}{|l|}{ Risk factors } \\
\hline & & & Blood draw $w^{c}$ & $\begin{array}{l}\text { Drugs or bio- } \\
\text { logical } \\
\text { agents }^{c}\end{array}$ & $\begin{array}{l}\text { Drugs or biological } \\
\text { agents requiring FDA } \\
\text { review }^{c}\end{array}$ & $\begin{array}{l}\text { Medical or edu- } \\
\text { cational } \\
\text { records }\end{array}$ & $\begin{array}{l}\text { lonizing } \\
\text { radiation }^{c}\end{array}$ & $\begin{array}{l}\text { Any inva- } \\
\text { sive proce- } \\
\text { dure }^{c}\end{array}$ & $\begin{array}{l}\text { Medical devi- } \\
\operatorname{ces}^{c}\end{array}$ & $\begin{array}{l}\text { Medical devices } \\
\text { requiring FDA } \\
\text { reviewc }^{c}\end{array}$ \\
\hline Model 1 & $-2(0.3) ;<.0001$ & $-1(0.3) ; .0002$ & $0.1(0.4) ; .8$ & NA & NA & NA & NA & NA & NA & NA \\
\hline Model 2 & $-2(0.3) ;<.0001$ & $-1(0.3) ; .0003$ & NA & $-0.3(0.3) ; .3$ & NA & NA & NA & NA & NA & NA \\
\hline Model 3 & $-2(0.3) ;<.0001$ & $-1(0.3) ; .0003$ & NA & NA & $0.3(0.3) ; .4$ & NA & NA & NA & NA & NA \\
\hline Model 4 & $-2(0.3) ;<.0001$ & $-1(0.3) ; .0003$ & NA & NA & NA & $0.2(0.2) ; .4$ & NA & NA & NA & NA \\
\hline Model 5 & $-2(0.3) ;<.0001$ & $-1(0.3) ; .0003$ & NA & NA & NA & NA & $-0.3(0.2) ; .2$ & NA & NA & NA \\
\hline Model 6 & $-2(0.3) ;<.0001$ & $-1(0.3) ; .0002$ & NA & NA & NA & NA & NA & $0.2(0.2) ; .3$ & NA & NA \\
\hline Model 7 & $-2(0.3) ;<.0001$ & $-1(0.3) ; .0002$ & NA & NA & NA & NA & NA & NA & $0.2(0.3) ; .4$ & NA \\
\hline Model 8 & $-2(0.3) ;<.0001$ & $-1(0.3) ; .0002$ & NA & NA & NA & NA & NA & NA & NA & $0.3(0.4) ; .5$ \\
\hline Model 9 & $-2(0.3) ;<.0001$ & $-1(0.3) ; .0002$ & $0.5(0.5) ; .3$ & $-0.5(0.5) ; .3$ & $0.3(0.3) ; .3$ & $0.08(0.2) ; .8$ & $-0.3(0.2) ; .2$ & $0.3(0.2) ; .1$ & $0.004(0.4) ; .9$ & $0.1(0.5) ; .8$ \\
\hline
\end{tabular}

FDA, US Food and Drug Administration; NA, not applicable.

avalues are "parameter estimate (standard error); $P$ value." Models 1-8 are for individual risk factors; Model 9 includes all risk factors.

${ }^{\text {bReference }}$ group = participants at Mayo Clinic in the Midwest.

'Risk factors. 
In 2015 , only $18 \%$ of people aged 65 or older were driving motorized vehicles, perhaps owing to cognitive and physiological decline $[27,28]$. Conceivably, the need to travel a longer distance to access a clinical trial might impose a greater burden in older people. However, in this study, rural participants were slightly older than urban participants (65 vs 64 years). The COVID-19 pandemic has fostered the utilization of technology-enabled solutions such as digital consent, virtual visits, and collection of data at home, often with remote sensors, which obviate the need for on-site visits, and may increase the access to clinical trials in the rural population in the future [29-32].

In this study, $221(76 \%)$ trials offered to reimburse expenses and/or remunerate participants. Although financial bonus is welcomed by participants, it is not usually the only reason to participate [11]. Participants weigh risks and personal benefits of trials, discuss their decisions with people they trust, and may also have a genuine interest to contribute to progress in science [11]. The proportion of urban participants was greater in trials that used ionizing radiation or medical devices that required FDA review. However, these factors did not remain significant after adjusting for location. This analysis did not evaluate the participants' perception of study risks, which influences their willingness to participate in a study [11]. Some interventions that are considered as risks (e.g., ionizing radiation or blood draw) may be regarded favorably by participants as a benefit of access to new or existing treatment with readily available services, and a chance to learn more about their condition [11].

Ultimately, lower rates of participation among rural residents and other minorities affect the generalizability of trial results. For instance, people of color often have a larger knowledge gap regarding clinical trials [33] and were underrepresented in important clinical trials that led to FDA oncology drug approvals [13]. This is a major problem given the large economic, educational, cultural, and social disparities between rural and urban areas [8]. Indeed, rural residents tend to be less healthy and arguably need greater access to trials than their urban counterparts [8]. Other factors that may hinder participation of rural patients in clinical trials include low health literacy, inadequate information about trials or understanding of the idea of clinical trials, negative perceptions about trials, fear of participating in trials, and lack of confidence in medical research [34-37]. Some of these factors also limit the access of rural patients to clinical care (e.g., adjuvant chemotherapy after colon cancer surgery) [38]. Besides these patient-related factors, rural physicians may be less aware, willing, or able to accrue patients into trials [36]. Trial investigators at major medical centers seldom reach out to individuals in medically underserved communities [39].

\section{Limitations}

Other factors that influence participation in clinical trials were not assessed in this study. The socioeconomic status can be evaluated with the Housing-based Socioeconomic Status index, which is derived from the home address, and predicts self-rated health, advanced care planning, nursing home utilization, and other indices $[40,41]$. Cultural differences between patients and health care providers, which can lead to miscommunication and mistrust and reduce the willingness of rural residents to participate in clinical trials, were also not assessed [42]. Selected chronic conditions (e.g., hypertension, obesity, heart and cerebrovascular disease, chronic obstructive pulmonary disease) are more common in rural than urban residents [8]. Since these conditions are often exclusion criteria in clinical trials, they may limit the enrollment of rural residents in trials [33]. In assessing the relationship between participant remuneration and urban versus rural status, the remuneration was categorized broadly rather than in granular detail (e.g., based on the quantum of actual expense reimbursement). A more granular assessment might uncover significant association(s) between reimbursement and participation. The approval process, funding, and timeline for enrolling participants are less predictable for nonindustry supported than industry-supported clinical trials. Hence, this study was limited to industry-supported clinical trials.

In this sample of patients from geographically distributed Mayo Clinic sites, approximately 1 in 3 clinical trial participants resided in a rural area compared to 1 in 5 residents in the population. Rural residents travelled further to access clinical trials. The study-associated risks were not associated with the distribution of rural and urban participants in trials.

Acknowledgments. This study was supported by Grant Number UL1 TR002377 from the National Center for Advancing Translational Sciences (NCATS). Its contents are solely the responsibility of the authors and do not necessarily represent the official views of the National Institutes of Health.

Disclosures. The authors have no conflicts of interest to declare.

\section{References}

1. Hartley D. Rural health disparities, population health, and rural culture. American Journal of Public Health 2004; 94(10): 1675-1678.

2. Bureau USC. New Census Data Show Differences Between Urban and Rural Populations. https://www.census.gov/newsroom/press-releases/ 2016/cb16-210.html. Published 2016. Accessed 5/5/2021, 2021.

3. Singh GK, Siahpush $\mathbf{M}$. Widening rural-urban disparities in life expectancy, U.S., 1969-2009. American Journal of Preventive Medicine 2014; 46(2): e19-e29.

4. Henley SJ, Anderson RN, Thomas CC, Massetti GM, Peaker B, Richardson LC. Invasive cancer incidence, 2004-2013, and deaths, 2006-2015, in nonmetropolitan and metropolitan counties - United States. Morbidity \& Mortality Weekly Report Surveillance Summaries 2017; 66(14): 1-13.

5. Krzyzanowska MK, Kaplan R, Sullivan R. How may clinical research improve healthcare outcomes? Annals of Oncology 2011; 22(Suppl 7): vii10-vii15.

6. Baquet CR, Commiskey P, Daniel Mullins C, Mishra SI. Recruitment and participation in clinical trials: socio-demographic, rural/urban, and health care access predictors. Cancer Detection \& Prevention 2006; 30(1): 24-33.

7. Seidler EM, Keshaviah A, Brown C, Wood E, Granick L, Kimball AB. Geographic distribution of clinical trials may lead to inequities in access. Clinical Investigation 2014; 4(4): 373-380.

8. Iglehart JK. The challenging quest to improve rural health care. New England Journal of Medicine 2018; 378(5): 473-479.

9. Winter SS, Page-Reeves JM, Page KA, et al. Inclusion of special populations in clinical research: important considerations and guidelines. Journal of Clinical \& Translational Research 2018; 4(1): 56-69.

10. Unger JM, Moseley A, Symington B, Chavez-MacGregor M, Ramsey SD, Hershman DL. Geographic distribution and survival outcomes for rural patients with cancer treated in clinical trials. JAMA Network Open 2018; 1(4): e181235.

11. Houghton C, Dowling M, Meskell $P$, et al. Factors that impact on recruitment to randomised trials in health care: a qualitative evidence synthesis. Cochrane Database of Systematic Reviews 2020; 10: Mr000045.

12. Hunsaker A, Sarles CE, Rosen D, et al. Exploring the reasons urban and rural-dwelling older adults participate in memory research. American Journal of Alzheimer's Disease \& Other Dementias 2011; 26(3): 227-234. 
13. Loree JM, Anand S, Dasari A, et al. Disparity of race reporting and representation in clinical trials leading to cancer drug approvals from 2008 to 2018. JAMA Oncology 2019; 5(10): e191870.

14. Robinson JC, Wyatt SB, Hickson D, et al. Methods for retrospective geocoding in population studies: the Jackson Heart Study. Journal of Urban Health 2010; 87(1): 136-150.

15. Watters JT, Pitzen JH, Sanders LJ, et al. Transforming the activation of clinical trials. Clinical Pharmacology \& Therapeutics 2018; 103(1): 43-46.

16. Agriculture USDo. Rural-Urban Commuting Area Codes [Internet], 2020 [cited May 5, 2021]. (https://www.ers.usda.gov/data-products/rural-urbancommuting-area-codes/)

17. Bureau USC Urban and Rural. [Internet] 2020 [cited May 5, 2021]. (https://www.census.gov/programs-surveys/geography/guidance/geo-areas/ urban-rural.html)

18. Beckman JP, Camp JJ, Lahr BD, et al. Pregnancy history, coronary artery calcification and bone mineral density in menopausal women. Climacteric 2018; 21(1): 53-59.

19. Frank Jr. H. Regression Modeling Strategies: With Applications to Linear Models, Logistic and Ordinal Regression, and Survival Analysis (Springer Series in Statistics). 2nd ed. New York, NY: Springer, 2015.

20. Costenbader KH, Brome D, Blanch D, Gall V, Karlson E, Liang MH. Factors determining participation in prevention trials among systemic lupus erythematosus patients: a qualitative study. Arthritis \& Rheumatology 2007; 57(1): 49-55.

21. Ferreira AP, Ramos PDS, Dornelas BR, Ferreira AF, Ricardo DR, Gomes Pereira DA. Challenges in recruitment and adherence to a randomized clinical trial in Brazil on the effects of transcutaneous nervous electrical stimulation on individuals with peripheral arterial disease: a feasibility study. Journal of Vascular Nursing 2020; 38(4): 164-170.

22. Friedman SH, Cunningham CO, Lin J, Haramati LB, Levsky JM. Having a primary care provider is the strongest predictor of successful follow-up of participants in a clinical trial. The Journal of the American Board of Family Medicine 2020; 33(3): 431.

23. Kanarek NF, Kanarek MS, Olatoye D, Carducci MA. Removing barriers to participation in clinical trials, a conceptual framework and retrospective chart review study. Trials 2012; 13: 237.

24. Azoulay P, Fishman AY. The Rise of For-Profit Experimental Medicine [Internet], 2020. (https://mitsloan.mit.edu/shared/ods/ documents/?PublicationDocumentID=6315)

25. Philippidis A. Top 50 NIH-Funded Institutions of 2020. Genetic Engineering and Biotechnology News Web site [Internet], 2020 [cited Feb 27, 2021]. (https://www.genengnews.com/a-lists/top-50-nih-fundedinstitutions-of-2020/)

26. Probst JC, Laditka SB, Wang JY, Johnson AO. Effects of residence and race on burden of travel for care: cross sectional analysis of the 2001 US National Household Travel Survey. BMC Health Services Research 2007; 7: 40.

27. Foley DJ, Heimovitz HK, Guralnik JM, Brock DB. Driving life expectancy of persons aged 70 years and older in the United States. American Journal of Public Health 2002; 92(8): 1284-1289.
28. Ikpeze TC, Elfar JC. The Geriatric driver: factors that influence when to stop driving. Geriatric Orthopaedic Surgery and Rehabilitation 2016; 7(2): 106-109.

29. Taylor DM, Stone SD, Huijbregts MP. Remote participants' experiences with a group-based stroke self-management program using videoconference technology. Rural Remote Health 2012; 12: 1947.

30. Bharucha AE, Rhodes CT, Boos CM, Keller DM, Dispenzieri A, Oldenburg RP. Increased Utilization of Virtual Visits and Electronic Approaches in Clinical Research During the COVID-19 Pandemic and Thereafter. Mayo Clinic Proceedings 2021; 96(9): 2332-2341.

31. Brezing CA, Luo SX, Mariani JJ, Levin FR. Digital clinical trials for substance use disorders in the age of Covid-19. Journal of Addiction Medicine 2020; 14(6): e297-e302.

32. Clark D, 3rd, Woods J, Patki D, et al. Digital informed consent in a rural and low-income population. JAMA Cardiology 2020; 5(7): 845-847.

33. Trant AA, Walz L, Allen W, DeJesus J, Hatzis C, Silber A. Increasing accrual of minority patients in breast cancer clinical trials. Breast Cancer Research and Treatment 2020; 184(2): 499-505.

34. Ford JG, Howerton MW, Lai GY, et al. Barriers to recruiting underrepresented populations to cancer clinical trials: a systematic review. Cancer 2008; 112(2): 228-242.

35. Bergeron CD, Foster C, Friedman DB, Tanner A, Kim SH. Clinical trial recruitment in rural South Carolina: a comparison of investigators' perceptions and potential participant eligibility. Rural \& Remote Health 2013; 13(4): 2567.

36. Tanner A, Kim SH, Friedman DB, Foster C, Bergeron CD. Barriers to medical research participation as perceived by clinical trial investigators: communicating with rural and African American communities. Journal of Health Communication 2015; 20(1): 88-96.

37. Unger JM, Vaidya R, Hershman DL, Minasian LM, Fleury ME. Systematic review and meta-analysis of the magnitude of structural, clini$\mathrm{cal}$, and physician and patient barriers to cancer clinical trial participation. Journal of the National Cancer Institute 2019; 111(3): 245-255.

38. Lin CC, Bruinooge SS, Kirkwood MK, et al. Association between geographic access to cancer care, insurance, and receipt of chemotherapy: geographic distribution of oncologists and travel distance. Journal of Clinical Oncology 2015; 33(28): 3177-3185.

39. Tanner A, Kim SH, Friedman DB, Foster C, Bergeron CD. Promoting clinical research to medically underserved communities: current practices and perceptions about clinical trial recruiting strategies. Contemporary Clinical Trials 2015; 41: 39-44.

40. Butterfield MC, Williams AR, Beebe T, et al. A two-county comparison of the HOUSES index on predicting self-rated health. Journal of Epidemiology and Community Health 2011; 65(3): 254-259.

41. Barwise A, Juhn YJ, Wi CI, et al. An individual housing-based socioeconomic status measure predicts advance care planning and nursing home utilization. American Journal of Hospice and Palliative Medicine 2018; 36(5):362-369.

42. Watts KA, Gazaway S, Malone E, et al. Community Tele-pal: a community-developed, culturally based palliative care tele-consult randomized controlled trial for African American and White Rural southern elders with a life-limiting illness. Trials 2020; 21(1): 672 . 